\title{
Broadening the Environmental Dimension in the Post-2015 Development Agenda
}

\author{
Adnan A. Hezri
}

\begin{abstract}
The MDGs recognise the nexus between human development and environmental sustainability through MDG 7. After more than a decade, however, the global progress on MDG 7 targets and indicators pales in comparison with progress on other MDGs. Even in an upper-middle-income economy like Malaysia, environmental sustainability is hardly an integral part of development practice despite its appreciation in key development policy documents. Albeit concise and measurable, MDG 7 has not only failed to produce enough positive results, it also fails to reflect the gravity of environmental challenges when it was conceived in early 2000. More acutely, there are emerging biophysical and economic realities at the global level demanding new development strategies. To stay relevant, sustainable development should be moved centre-stage in the quest to reimagine the international development agenda after 2015.
\end{abstract}

\section{Introduction}

Environmental sustainability is the cornerstone of human development, providing the water, food, air and materials that humanity relies on. The seventh Millennium Development Goal (MDG 7) aims for environmental sustainability. Just like MDGs 1-6, its indicators are quantified, timebound and encourage quick-win initiatives where environmental problems can be addressed while alleviating poverty. Apart from functioning as a guideline for coordinated action, the goal serves to mobilise political commitment and generate popular awareness around consensus development objectives (Jolly 2010: 49).

It initially includes three targets:

- Integrate the principles of sustainable development into country policies and programmes and reverse the loss of environmental resources (Target 7A);

- Halve, by 2015, the proportion of the population without sustainable access to safe drinking water and basic sanitation (Target 7C); and

- Achieve, by 2020, a significant improvement in the lives of at least 100 million slum dwellers (Target 7D).
In 2002, the target 'to achieve by 2010 a significant reduction of the current rate of biodiversity loss' from the United Nations Convention on Biological Diversity was incorporated into the MDGs (Target 7B) (Sachs et al. 2009). This move marks international recognition of biodiversity as a factor crucial to human development. It also demonstrates the highest-level acknowledgement of the signals of unsustainability and disturbance of the planet's natural systems.

This article unpacks the issues surrounding the position of MDG 7 in the context of the unfolding Post-2015 Development Agenda. First, it surveys the utility of targets and indicators of MDG 7 as a measure of environmental sustainability, and tracks the global progress to date. It then examines the crucial question of how to operationalise environment in the MDG process, within the public policy context of an upper-middle-income country of Malaysia. The final section identifies the emerging development challenges and outlines the possible scenarios of how sustainable development could be moved centre-stage in the quest to reimagine the international development agenda after 2015. 


\section{Environmental sustainability and MDGs 2.1 Progress of MDG 7}

The MDG picture for environmental sustainability is one of conditional optimism. The 2012 annual report of the United Nations, which monitors progress on the MDGs, records the following results (UN 2012). With respect to Target 7C, the world has met the target of halving the proportion of people without sustainable access to safe drinking water by 2010 . However projections indicate that in 2015 more than 600 million people worldwide (especially those living in countries with greater socioeconomic problems) will still be using unimproved water sources, rendering future access uncertain.

The greatest challenge for Target $7 \mathrm{C}$ lies with access to modern sanitation, with 2.5 billion people in developing countries still deprived of this service. The number of people practising open defecation remains a widespread health hazard. This is indirectly hampering progress in health and nutrition MDGs. However the access to sanitation figure has increased from 36 per cent in 1990 to 56 per cent in 2010 in the developing regions as a whole, with Eastern and Southern Asia making the greatest progress.

With Target 7B, the world has missed the 2010 objective for biodiversity conservation. Based on current trends, the loss of species will continue throughout this century even as more areas of the earth's surface are protected. Moreover, half of the world's most important terrestrial sites for species conservation remain unprotected.

With respect to Target $7 \mathrm{D}$, improvements in the lives of 200 million slum dwellers bring achievement of the MDG target ahead of the 2020 deadline. The share of urban slum residents in the developing world declined from 39 per cent in 2000 to 33 per cent in 2012. The reduction in the percentage of urban population living in slums notwithstanding, the absolute number of slum dwellers continues to grow and the projections of rapid urbanisation foretell a mounting pressure in the near future. This uncertainty is also seen in Target 7A with regard to the integration of sustainable development into country policies and programmes. Good progress on some issues such as forest area increase in Asia is helping to slow, but not reverse, global losses worldwide. Similarly, the ongoing economic crisis pushes down global greenhouse gas emissions only slightly, attributable to slowing economic activity. This, however, is expected to be only a short-term change rather than a permanent one.

Although the environment is recognised as a precondition to the achievement of the MDGs, it is poorly mainstreamed in public policy (UNDP 2006). In summary, the sustainable use of ecosystem services is hardly an integral part of development strategies across the world when compared to other MDGs such as health and education. Consequently, there is a chorus of analyses and opinions doubting that the world is to make the targets for environmental sustainability.

\subsection{Gaps in the current MDG 7}

Unlike other established UN development goals such as health and education (Jolly 2010), MDG 7 is relatively ahistorical and contains fewer concrete goals and indicators in comparison with the rest of the Millennium Declaration (von der Hoeven 2012). The early interest in developing environmental indicators in the 1970s was mainly to support environmental monitoring for the incipient environmental agencies in developed countries. Hence, environmental goals fall mainly within the purview of national governments and do not form part of the international development agenda. But since then, combining global with local initiatives, there are literally thousands of efforts to define and measure appropriate indicators of environmental sustainability. Any attempts to garner a homogenous view of the goals of environmental sustainability among scholars and practitioners are therefore fruitless. Consequently, numerous criticisms are mounted against MDG 7, including errors of omission (Castello et al. 2010), the separation of environment into one of eight goals (Roe and Elliot 2004), and misplaced priority (see, for example, Langford 2010). At the extremes there are claims that Goal 7 for the environment is the MDGs' biggest shortcoming.

As a trade-off for simplicity and communicability, the framing for environmental sustainability has been minimised and does not capture the complexity and breadth of the challenge. Only a small subset of issues is covered. For instance, the goal makes no reference to key environmental issues such as land degradation, population growth and the eroding natural resource base that are so important for continuous human development in the developing world. 
There are also issues surrounding the impotence of the chosen indicators to reflect their respective targets. Although the world has met Target 7C five years ahead of schedule, 'halving the proportion of people without access to improved sources of water' is a very limited conception of the developing world's water agenda. Absent in the current framework is holistic thinking emphasising that access to water and sanitation depends on the availability of healthy ecosystems that are managed sustainably. The connection of environmental indicators to the social dimension through the poverty-environment link is also weak.

Indicators on protected areas and forestry, for example, do not reflect critical changes affecting the poor such as land degradation and desertification. The view that MDG 7 is fragmented and does not integrate the different components of environmental sustainability well is shared by the United Nations Development Group (UNDG 2010) in its thematic assessment, pointing out that the components do not provide a full picture.

The holy grail of a 'comprehensive picture' with strong linkages between goals is constrained by the complexity of environmental sustainability for two reasons. First is data availability and comparability at the international levels for key sustainability challenges such as biodiversity loss and climate change mitigation or adaptation. When data are absent even proxies are hard to agree upon because of the complexity of the environment. Second, although problems like water scarcity, nitrogen pollution, and transboundary air pollution have clear risk tractability and scientific evidence, the international policy mechanism for defining the problem and organising the response is lacking. So, the problems with MDG 7 not only lie with measurement but also the fact that the choice of indicators is highly politicised at the international level.

\section{The impact of the MDGs on development policy in Malaysia}

Although progress has been uneven, the MDGs have helped to galvanise a significant scaling-up policy response on the eight goals across the world during the past decade. Malaysia is one of 194 United Nations member states supporting the MDGs. Historically it has institutionalised human development since Independence in 1957 with a remarkable record in poverty alleviation. With a population of 28.7 million, the country belongs to the upper-middle-income club and is currently instigating reforms to graduate into a high-income country.

\subsection{MDG policy process in Malaysia}

Although the MDGs are seen by many countries as a UN agenda (rather than national political priority) the MDGs were widely accepted by policymakers in Malaysia from very early on because human-based development has always been its development philosophy. Malaysia has institutionalised human development since Independence. Hence, for the Malaysian government, the MDGs framework is one of the international goal-sets consistent with its policy objectives. In many official documents, it is often claimed that Malaysia has the resources, the capacity and the know-how to address the basic problems affecting human development. These are not unfounded. Infant mortality, now at six per 1,000 live births, is comparable to the most advanced countries. Universal primary education for boys and girls was achieved in 1990. All boys and girls are enrolled at primary school level, and enrolment rates exceed 80 per cent at lower secondary level. Investment in human capital, especially in health and education, is another hallmark of the Malaysian model. For these reasons, even though considered as a lowhanging fruit for its modest target, the MDGs framework is also seen by many officials as a 'doable' regular reporting obligation to the international agencies.

\section{In 2005, the country assessment on MDG} achievement showed that Malaysia was 'on track' with six out of eight targets. The results are echoed by a recent regional MDG assessment which categorised Malaysia as an early achiever for the following goals and targets:

- Goal 1 - US\$1.25 per day, underweight children;

- Goal 2 - Primary enrolment, primary completion;

- Goal 3 - Gender primary, gender secondary, gender tertiary;

- Goal 6 - TB incidence, TB prevalence; and

- Goal 7 - Protect areas to maintain biological diversity; reduce ozone-depleting substances (ODS) consumption; improve water access and sanitation. 
Given that most of the progress in some targets such as income poverty is attributable to pre-MDG efforts, how do we assess its influence in policymaking and policy dialogues within the country?

\subsection{Socialisation of the MDGs in public policy}

In official terms, references to the MDGs appeared in the Ninth Malaysia Plan document released in 2005. To date, there have been two assessments of MDG implementation in Malaysia. The first, initiated in 2004, was a collaborative effort between the Country Team of UNDP (UNCT) and the Economic Planning Unit (EPU) of the Prime Minister's Department. The EPU established an Inter-Ministerial Steering Committee to provide inputs and coordinated extensive consultation with civil society groups. The UNCT and the Malaysian government organised two consultative workshops with NGOs, the media and academe to seek their views on Malaysia's successes and challenges in progressing towards the MDGs. The assessment team endeavoured to raise awareness of human rights and their links to MDGs through these consultations. A notable achievement of these consultations was bringing the Human Rights Commission of Malaysia, the government and NGOs together to debate development issues through a human rights lens. The consultation process also involved a number of workshops on 'localising the MDGs' in the East Malaysian states.

As a result of the various consultative processes, the government released a publication entitled Malaysia: Achieving the Millennium Development Goals: Successes and Challenges (UNDP 2005). It provides a detailed account of the policies, strategies and programmes on a goal-by-goal basis that had enabled Malaysia to meet most of the MDGs. This publication was officially launched by the Prime Minister of Malaysia on 28 January 2005. In conjunction with the launch, an international conference was held concurrently to share best practices with a number of Asian and Southern countries as well as members of civil society, both local and international. At the United Nations General Assembly on 14 September 2005, the Prime Minister presented the report, outlining Malaysia's progress in implementing the eight MDGs.

The second MDG assessment was initiated in January 2010. The UNDP Country Team had tasked seven individual consultants to review achievement on eight targets. The individual reports were synthesised into a three-page document for the Prime Minister's speech on the MDGs to the UN General Assembly in New York. The findings from this assessment were later published in a report entitled Malaysia: The Millennium Development Goals at 2010 which was released in 2011 (Economic Planning Unit and UN 2011). Notably, the country has largely achieved the MDG objective of eradicating poverty, which fell from 17 per cent in 1990 to 3.8 per cent in 2009, based on the national poverty line. It has also achieved gender parity at all levels of education, surpassing parity at the national level. For these reasons, the government has outlined its commitment to the MDG-Plus agenda through its Tenth Malaysia Plan (2011-2015), with 30 per cent of development expenditure allocated to the social sector. In addition to the aggregate assessment at the national level, the 2010 review also adopts a disaggregated view of the MDGs by looking at performance at sub-national levels by state, rural/urban location, gender, ethnicity, age group and other disaggregated categories. One important finding is the stark picture of regional inequality in the incidence of poverty.

\subsection{Policy changes}

A number of 'symbolic' measures of MDG mainstreaming are commonly observed in Malaysia. For instance, MDGs feature invariably in the premier's and ministerial speeches, especially around key MDG years such as 2004/05 and 2010. Another measure of integration is when reference is made to the MDGs in key development documents such as the Ninth Malaysia Plan. Despite strong mention of the MDGs in the Ninth Malaysia Plan, however, the Tenth Malaysia Plan contains no reference to this global goal.

Besides the 'integration' of MDGs into government documents, media coverage of MDGs is another means to gauge their conceptual influence or penetration in Malaysia's policy process. A simple search for MDGs in a local press database for four newspapers returned close to 100 hits. Poverty and health (HIV/AIDS in particular) are the most frequently discussed MDGs, while MDG 7, the environment, is the least often referred to (Hezri 2012). 
A credible institutional response to the MDGs is crucial in ensuring new rules and patterns of control are firmly entrenched in the logic of development practices. Examples of instrumental integration include the following.

- Organisational - The EPU is appointed as a coordinating agency, and the National Steering Committee is established.

- Informational - The Department of Statistics Malaysia responded to the MDGs' informational requirement by establishing and hosting an interactive Malaysia Info Database containing data on MDG indicators.

- Programmatic - An extended Theme Group on HIV/AIDS was established in 2004 and included representatives from government and civil society, as well as United Nations Country Team members. The main thrust of its work was to give momentum to the development of a revised National Strategic Plan on HIV/AIDS. Due in part to the work of the Country Team, a revised draft National Strategic Plan was developed and endorsed by government.

The pitfalls of global target-setting were revealed immediately when some countries began boasting of success within a few years of the Millennium Declaration. This is particularly the case in middle-income countries which already had more ambitious targets or possessed the capacity to quickly halve or address smaller gaps. Governments pick and choose according to their own tastes in highlighting success or hiding failures. Malaysia is no exception to this phenomenon. For poverty, the targets are problematic in being largely unfocused on the poorest of the poor. Furthermore, inequality is still an issue because poverty levels still vary considerably by state and ethnic groups. Both challenges are not widely openly discussed.

\subsection{MDG 7 in Malaysia}

The environmental MDG registers specific challenges. Broadly, after decades of struggle to create concrete programmes to address regressive environmental trends, it has become clear to policymakers and environmental activists alike that there is a gap between the objectives and the implementation of sustainable development policies. In reality, it is extremely hard to bridge the gap between stated policy goals and practical strategies to achieve those goals. The main difficulty is to overcome the distinctly resilient patterns of production and consumption associated with conventional paths of economic development.

The latest MDG assessment commissioned by UNDP-EPU analysed performance on ten indicators. Evaluation of MDG 7 achievement is more difficult than with health-related MDGs. The environment portfolio in the Malaysian government cuts across six ministries and 22 government agencies. Some indicators are performing well within the MDG analytical framework. Access to water supply in Malaysia is excellent. Be that as it may, urban residents are faced with increasing episodes of water supply disruptions. Also, although the percentage of the population with access to improved sanitary facilities was recorded at 97 per cent in 2007, untreated sewage is still causing bacterial contamination of waterways and coastal waters. In energy use, indicators show that much effort will be needed to reduce energy use by increasing efficiency and shifting to renewable sources.

How does Malaysia fare when compared with other nations on related sustainability metrics? In a 2005 study benchmarking the performance of 146 countries on an Environmental Sustainability Index, Malaysia ranked 38th. This was not a particularly comfortable result for the country because other mega-(bio)diverse nations such as Brazil, Argentina and Costa Rica all ranked higher on the index (Hezri and Dovers 2011). On the 2010 Climate Change Performance Index, which rates the emission levels, emission trends and climate policies of the world's 57 largest carbon dioxide emitters, Malaysia appeared in the bottom-ranked group of countries alongside countries like Canada, Australia, the USA and Saudi Arabia. On the biodiversity side, the 2008 Red List of Threatened Species published by the International Union for Conservation of Nature (IUCN) ranked Malaysia as the country with the third-highest number of endangered species $(1,141)$, after only Ecuador $(2,208$ species $)$ and the USA (1,192 species).

Methodological issues at times influence the interpretation of an indicator. For instance, for land area under forest cover, Malaysia's official figure has changed from 56 per cent to 62.4 per cent simply because the Food and Agriculture 


\begin{tabular}{|c|c|c|c|}
\hline & $\begin{array}{l}\text { Scenario } 1 \\
\text { MDGs continuation and } \\
\text { incremental modification }\end{array}$ & $\begin{array}{l}\text { Scenario } 2 \\
\text { MDGs continuation } \\
\text { and radical modification }\end{array}$ & $\begin{array}{l}\text { Scenario } 3 \\
\text { SDGs replacing MDGs }\end{array}$ \\
\hline $\begin{array}{l}\text { What might such a target } \\
\text { be called or look like? }\end{array}$ & $\begin{array}{l}\text { Ensuring sustainability } \\
\text { through climate-resilient } \\
\text { and low-carbon } \\
\text { development }\end{array}$ & $\begin{array}{l}\text { Operating within a safe } \\
\text { operating space }\end{array}$ & $\begin{array}{l}\text { 'Bullseye' or MDG-styled } \\
\text { targets versus 'jigsaw puzzle' or } \\
\text { harmonisation of disparate } \\
\text { sustainable development goals }\end{array}$ \\
\hline $\begin{array}{l}\text { What will the guiding } \\
\text { principles be? }\end{array}$ & $\begin{array}{l}\text { Addition of new targets } \\
\text { and new indicators or } \\
\text { integrate climate concerns } \\
\text { into all } 8 \text { MDGs }\end{array}$ & $\begin{array}{l}\text { Shift from concentrating } \\
\text { on available statistics to } \\
\text { new measurement at } \\
\text { national level }\end{array}$ & $\begin{array}{l}\text { SDGs deserve deeper analysis } \\
\text { of interconnections and } \\
\text { synergies between goals, } \\
\text { trade-offs, and indicators and } \\
\text { targets }\end{array}$ \\
\hline $\begin{array}{l}\text { What indicators might be } \\
\text { included to measure } \\
\text { progress? }\end{array}$ & $\begin{array}{l}\text { Renewables penetration; } \\
\text { energy efficiency } \\
\text { achievements; access to } \\
\text { strategic resources such as } \\
\text { water, energy and food } \\
\text { (or the WEF nexus); } \\
\text { integrate climate change } \\
\text { initiatives into national } \\
\text { development plan; loss of } \\
\text { ecosystem services }\end{array}$ & $\begin{array}{l}\text { Indicators include: change } \\
\text { in land use; global } \\
\text { freshwater use; ocean } \\
\text { acidification; phosphorous } \\
\text { cycle; biodiversity loss; } \\
\text { climate change; nitrogen } \\
\text { cycle; and additional } \\
\text { indicators from MEA } \\
\text { (Millennium Ecosystem } \\
\text { Assessment) to focus on } \\
\text { ecosystem services }\end{array}$ & $\begin{array}{l}\text { Thriving lives and livelihoods, } \\
\text { sustainable food security, } \\
\text { sustainable water security, } \\
\text { universal clean energy, healthy } \\
\text { and productive ecosystems, and } \\
\text { governance for sustainable } \\
\text { societies }^{2}\end{array}$ \\
\hline
\end{tabular}

Organization (FAO) had recently considered rubber plantations as 'forested area'. This renders Malaysia 'on track' for this indicator. Omission of nationally important indicators is a recognised weakness of the MDGs. As globally set goals, key environmental challenges in Malaysia such as waste management and pollution are not measured in the list of ten indicators. Plus, there are also signs of false or motivated reporting to keep government agencies under or over a line of convenience. This and earlier discussions argue against a sole reliance on MDGs to streamline development efforts, set national priorities and focus action.

\section{Post-2015 Development Agenda \\ 4.1 Emerging challenges}

Three realities strengthen the case for a new development agenda. First, development challenges have become more pressing since 2000 when the MDGs were conceived. Growing evidence of planetary change convincingly demonstrates that humanity is now a geological force that has ushered in a new epoch called the Anthropocene. Fresh scientific findings suggest that we are now approaching limits in global resource availability and sink strength. Many indicators point to unprecedented planetary changes such as biodiversity loss, climate change and nitrogen removal from the atmosphere (Rockstrom et al. 2009). These changes are happening because of economic growth in both high-income and developing economies, driven by continuous striving for improvements in material welfare. If left unchecked they are real dangers that could threaten development and trigger humanitarian crises across the globe.

Second, albeit concise and measurable, the unambitious environmental sustainability goal is not only unreflective of the gravity of environmental challenges, it also lacks enough positive results. The rate for deforestation shows signs of decrease, but the global biodiversity condition is alarmingly 'off track' and continues to decline. In addition, greenhouse gas emissions are likely to increase. The Intergovernmental Panel on Climate Change (IPCC) states that the existing pattern of failure in achieving the MDGs correlates with areas where high climate vulnerabilities are expected.

Third, the Rio+20 summit of 2012 has laid out some new and inspiring pathways for 
transitioning towards a green economy. It also opens a political space to resolve the apparent tension between the poverty goal and the sustainability of the planet. Herein lies an opportunity to strike a radical shift towards more sustainable patterns of consumption and production and resource use but couched in the reality of poverty eradication and sustainable development. Another policy innovation from Rio +20 is the proposal to develop Sustainable Development Goals (SDGs) as a part of the Post2015 Development Agenda. Any new or revised goals for the environment ideally will embrace broader notions of wealth encompassing natural capital, address environmental challenges directly, and enhance the livelihoods and resilience of the poor.

\subsection{Post-2015 criteria and scenarios}

These emerging challenges demand a post-2015 development framework that recognises that human development and a healthy planet can coexist. To reimagine a new development agenda, the five criteria listed below should guide the integration of sustainable development in the unfolding framework.

\section{Focus on economic development (as opposed to solely} international aid). The real causes of poverty and low growth levels is the absence of an industrial sector. ${ }^{1}$ Hence, ways must be found to develop the industrial and services sectors in order to lastingly improve the living conditions of people living in developing countries.

\section{Frame a joint policy agenda for climate and economic} development. One alternative development strategy is to implement green economy (or growth) with an increasing role for the private sector (P-P-P).

3 Change the logic of international cooperation. Developing countries may hesitate to open up for global scrutiny unless there is a commitment to joint action. Funding mechanisms that move beyond reducing the externalities of underdevelopment (e.g. combating the poverty trap) should be explored.
4 Reduce the burden and complexity of reporting. MDGs impose a large data collection and reporting burden on under-resourced government offices in the developing world. Combining MDGs and SDGs will maximise resources and avoid duplication and free up more resources for policy implementation.

\section{Design universal goals with targets that are relevant} to national contexts. Goals should universally apply but international reporting of MDGs must follow the combination of these two rules. One, the indicators are harmonised at the international level so that every country reports the same statistics. Two, indicators are selected by individual countries but must fall within specific categories established by an international reporting agreement (core or headline indicators).

Criteria (4) and (5) beg the question of possible scenarios for the Post-2015 Development Agenda. Essentially there are two possibilities a dual-track measure whereby MDGs and SDGs are developed as separate measures, or a single track measure in which MDGs and SDGs are combined. The two possibilities give rise to three scenarios as shown in Table 1 . The central tenet guiding all three scenarios is that long-term social and economic improvement will require closer attention to the environment.

A future development agenda as listed above will stand a better chance of addressing the complexity of sustainable development and the linkages among its multiple dimensions.

\section{Concluding remarks}

The MDGs have proven to be a powerful tool for international efforts to eradicate poverty and focus action towards meeting education, public health and the environmental goals. Be that as it may, to further mainstream environmental sustainability a more comprehensive set of principles and metrics are needed to design appropriate goals, targets and indicators. There is also a need to rethink international partnerships to foster low-carbon economic development across the developing world. 


\section{Notes}

1 One of the problems of the MDGs over recent decades is that developed countries are investing more in humanitarian aid than in development programmes.

\section{References}

Castello, Lucas D.; Gil-Gonzalez, Diana; Diaz, Carlos Alvarez-Dardet and HernandezAguado, Ildefonso (2010) 'The Environmental Millennium Development Goal: Progress and Barriers to its Achievement', Environmental Science and Policy 13: 154-63

Economic Planning Unit and UN (2011) Malaysia: The Millennium Development Goals at 2010, Kuala Lumpur: United Nations Country Team

Griggs, David; Stafford-Smith, Mark; Gaffney, Owen; Rockström, Johan; Öhman, Marcus C.; Shyamsundar, Priya; Steffen, Will; Glaser, Gisbert; Kanie, Norichika and Noble, Ian (2013) 'Sustainable Development Goals for People and Planet', Nature 495: 305-07

Hezri, Adnan A. (2012) 'Towards Human Security: The Implementation of MDGs in Malaysia', in H. Kraft (ed.), Mainstreaming Human Security in ASEAN Integration: Volume 2, Manila: Institute for Strategic and Development Studies-Japan International Cooperation Agency (ISDS-JICA): 198-222

Hezri, Adnan A. and Dovers, Stephen R. (2011) 'Shifting the Policy Goal from Environment to Sustainable Development', in Hal Hill, Tham Siew Yean and Ragayah Haji Mat Zin (eds), Malaysia's Development Challenges: Graduating from the Middle, Abingdon: Routledge: 276-95 Jolly, Richard (2010) 'The MDGs in Historical Perspective’, IDS Bulletin 41.1: 48-50
2 These six SDGs are proposed by Griggs et al. (2013) by combining the MDG targets with 'planetary boundary indicators', updated and extended for 2030.

Langford, Malcolm (2010) 'A Poverty of Rights: Six Ways to Fix the MDGs', IDS Bulletin 41.1: 83-91 Rockstrom, Johan, et al. (2009) 'A Safe Operating Space for Humanity, Nature 461: 472-5

Roe, Dilys and Elliott, Joanna (2004) 'Poverty Reduction and Biodiversity Conservation: Rebuilding the Bridges', Oryx 38: 137-9

Sachs, Jeffrey D., et al. (2009) 'Biodiversity Conservation and the Millennium Development Goals', Science 325: 1502-3

UN (2012) The Millennium Development Goals Report 2012, New York: United Nations

UNDG (2010) Thematic Paper on MDG 7 Environmental Sustainability, New York: United Nations Development Group

UNDP (2006) Making Progress on Environmental Sustainability: Lessons and Recommendations from a Review of Over 150 MDG Country Experiences, New York: United Nations Development Programme

UNDP (2005) Malaysia, Achieving the Millennium Development Goals: Successes and Challenges, Kuala Lumpur, United Nations Country Team: United Nations Development Programme von der Hoeven, Rolph (2012) MDGs Post-2015: Beacons in Turbulent Times or False Lights?, background paper prepared for UN System Task Team on the Post-2015 UN Development Agenda, www.un.org/millenniumgoals/pdf/ rolph_van_der_hoeven.pdf (accessed 24 April 2013) 